\title{
Experiment in infiltration studies as a water treatment process
}

\author{
Sylwia Kołaska ${ }^{1}$, Joanna Jeż-Walkowiak ${ }^{1, *}$, and Zbysław Dymaczewski ${ }^{1}$ \\ ${ }^{1}$ Poznan University of Technology, Institute of Environmental Engineering, 61-131 Poznań, ul. Berdychowo 4, Poland
}

\begin{abstract}
This article contains the concept of research methodology of the water infiltration process. The described research was conducted at Dębina intake in Poznan, Poland. Based on the temperature variation curves, it was possible to determine the water retention time in the ground during the flow of water from the infiltration pond through piezometers to the collecting well
\end{abstract}

\section{Introduction}

The infiltration process for surface water treatment is often taken into account because of the high efficiency of this process and economic considerations. In the infiltration process without use of chemical reagents, we obtain a high degree of water treatment [1-6]. Characteristic pollutants of surface waters - such as suspension, organic compounds, pharmaceuticals bacteria, Cryptosporidium or cyanobacteria toxins are being removed [7-9] and the quality of water after the infiltration process is comparable to the quality of groundwater [4-6]. Comparing the complexity of surface water treatment systems with groundwater treatment systems and considering deficiency of groundwater at the same time, it is appropriate to practice artificial infiltration process $[10,11]$. Infiltration process might be consider as a sustainable process, effectively reducing the amount od reagents applied at water treatment plant.

The paper presents research conducted on the area of Debina infiltration intake in Poznan, Poland. Intake was chosen due to location and long term proper operation.

\section{Brief description of Debina intake}

Debina infiltration intake is located by the warta river between 247 to $251 \mathrm{~km}$. There are located three rows of wells. The first row of wells is $80 \mathrm{~m}$ from the river, the second row of wells is $260 \mathrm{~m}$ from the river and the last is $340 \mathrm{~m}$. Wells located directly by the river collect water from riverbank infiltration and artificial infiltration, next two rows of wells collect water only from artificial infiltration. Wells collect water from a depth of $10-18 \mathrm{~m}$. The best water quality is obtained from the wells located $260 \mathrm{~m}$ from the river. In this localization water comes only from artificial infiltration and is separated from pollutions coming from outside the intake. The current capacity of debina intake is about $80000 \mathrm{~m}^{3} / \mathrm{d}$. At present, modernization works are being performed. The modernization aims to restore the original intake capacity, achieved before a 2 motorway construction $-100000 \mathrm{~m}^{3} / \mathrm{d}$. The balance of supply of debina intake is $[1,2]$ :

- artificial infiltration through infiltration ponds 65 $76 \%$;

- riverbank infiltration $16-27 \%$;

- groundwater inflow $8-12 \%$;

- rain water and melting waters - a few percent.

\section{Methods and scope of research}

Presented data are from preliminary work which had been done at debina intake. The research was conducted weekly. Measurement points were located along the second row of wells. To determine the water retention time in the ground, the following points were used: pond 3a, piezometers: i r./6, i r./7, well 37/ii, piezometers: i r./8, i r./ 9, pond 9 (Fig. 1). Piezometer i r./6 is located about 15 meters from the pond 3a. Then there is piezometer i r./7 at a distance of 40 meters from piezometer i r./6. The distance to well 37/ii from piezometer i r./7 is about 24 meters. From the other side we have piezometer i r./9 at a distance of about 14 meters from the pond 9. Another piezometer i r./8 is about 44 meters away from piezometer i r./9. Well 37/ii is about $24 \mathrm{~m}$ from piezometer i r./8 (Fig. 1).

An important parameter measured directly at debina intake was water temperature. Based on the determined temperature variation curves, it is possible to determine the water retention time in the ground during the flow of water from the pond through piezometers to the collecting well. In wells the temperature was always measured at the same depth. When it comes to piezometers, the temperature was measured every meter, starting with the first full meter below the dynamic water level, and ending with the last full meter before the bottom of the piezometer.

In research work, this non-invasive method of determining retention time was selected. It was mainly chosen to eliminate any interference in the work of the intake and to simplify carrying out measurements.

To determine the water quality change during the

Corresponding author: joanna.jez-walkowiak@put.poznan.pl 
passage through the ground the chemical analysis in water sample taken from ponds, piezometers and wells was done. Three series of samples were taken for laboratory analysis. In the facilities from which water was collected for analysis, pumping was always carried out at least twice to replace the volume of water before taking the sample.

\section{Results and interpretation}

\subsection{Determination of water retention time in the ground}

Water retention time in ground from pond $3 \mathrm{a}$ to piezometer I r./6 was assessed for 3 days, according to the water temperature drop after the decrease of air temperature. The water temperature drop took place 3 days after the air temperature decrease.

The retention time of water at the distance from the piezometer i r./6 to i r./7 was estimated at about 3 weeks. In the piezometer nearer to the pond, the water temperature rises from 25.04.2013 and in piezometer i r./7 (Fig. 2) 17.05.2013 - 3 weeks later (Fig. 3). In addition, there can be seen characteristic pattern of water temperature drops in piezometer i r./6 14.02.2013, which results in a drop in water temperature 07.03.2013 in piezometer i r./7, which also gives a three week retention time.

Comparing the air temperature in November 2012 (Fig. 2 ) with the course of the water temperature curve in piezometer $\mathrm{i} \mathrm{r} . / 7$, it was noted that the temperature drop of 14.12.2012 in the piezometer was most likely due to lower air temperatures in the period of 15-18 November. After these days, the temperature of the air increased as it was in case of temperature distribution of the piezometer. It is less than 4 weeks. Knowing that a few days is retention to the first point of measurement, estimated three weeks of retention between them are correct.

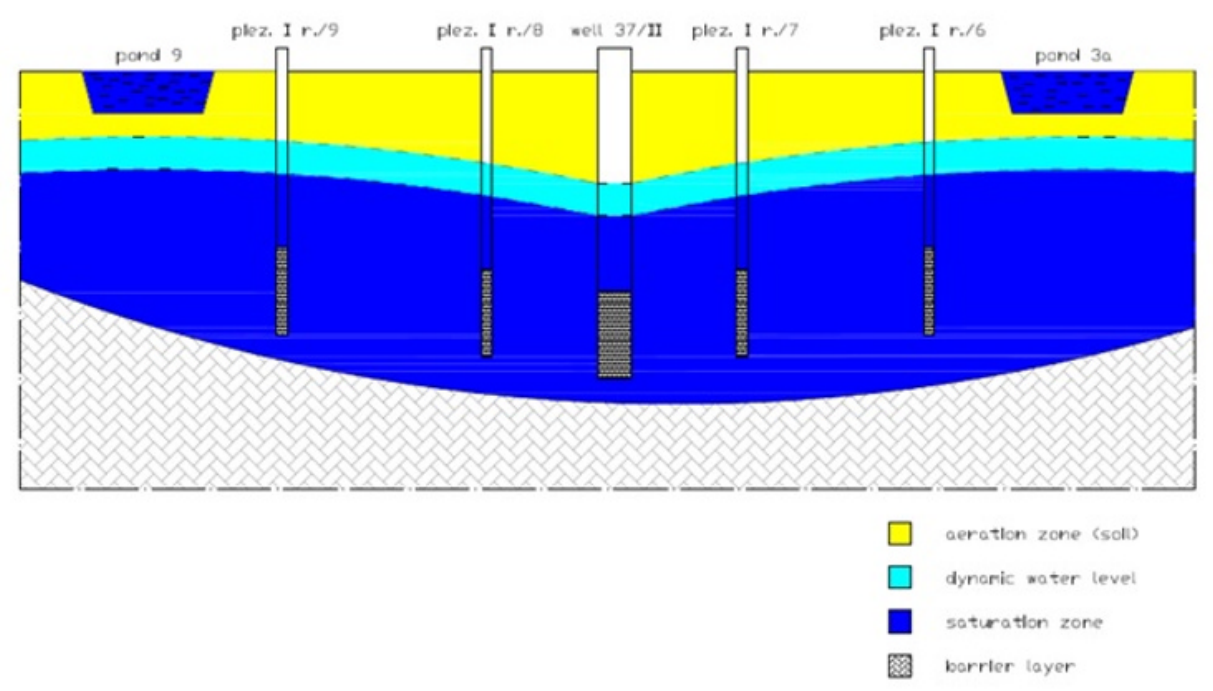

Fig. 1. Scheme of arrangement of measurement points.
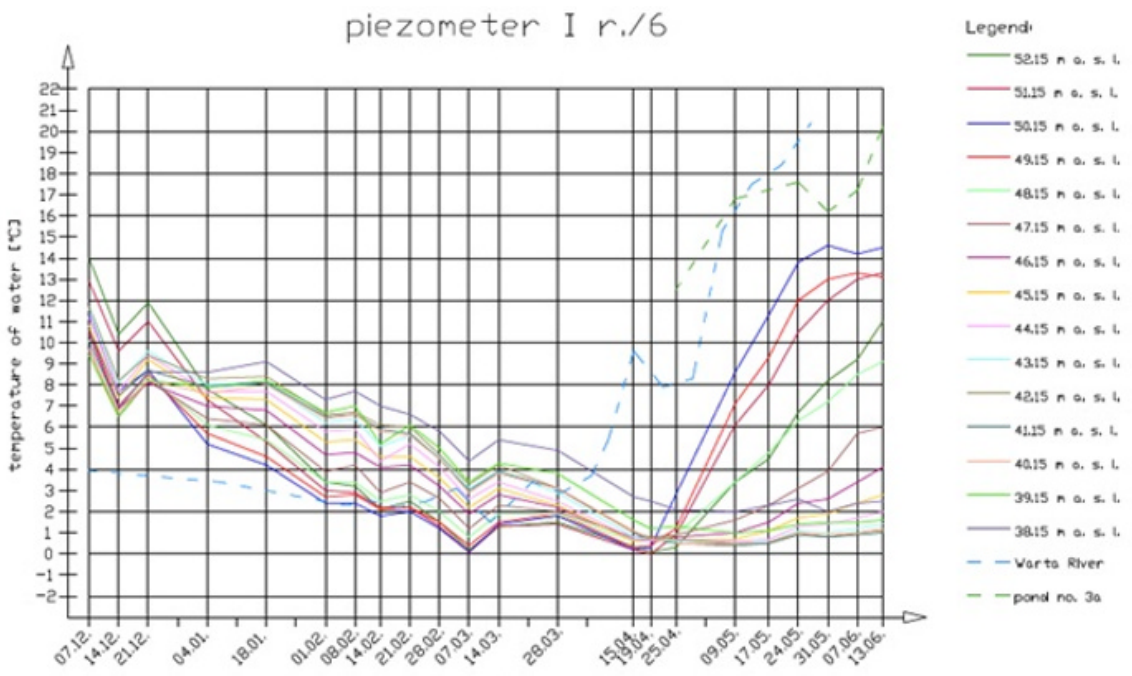

dote [dd-rn]

Fig. 2. Temperature of water in the piezometer I r./6. 


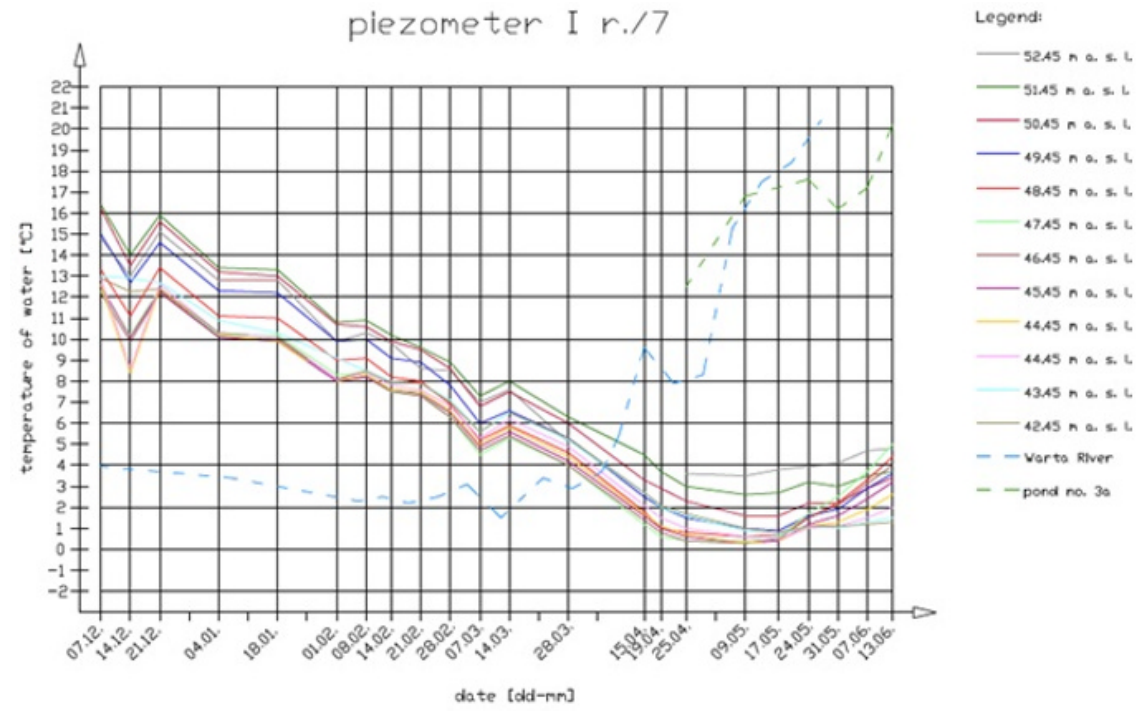

Fig. 3. Temperature of water in the piezometer I r./7

Water retention time between pond 9 and piezometer I r./9 is, as in the case of remaining piezometers located directly at ponds, several days. Water retention between two piezometers I r./9 and I r./8 takes about two weeks. Water flow time from piezometers to well $37 / \mathrm{II}$ was estimated to be 7 weeks.

\subsection{Variability of chemical parameters of water}

Under the influence of the infiltration process, surface water introduced into the ground through the infiltration ponds acquires properties similar to groundwater. The most representative results of the changes in water quality were found to be variations in the concentration of iron in the infiltration water.

The analysis of iron concentration in water samples was carried out with respect to the sequence of measurement points, from the ponds to the wells, starting with the shortest ground retention time. Presented results come from two measurement series made on 19.04.2013 and 24.05.2013.

To illustrate the change of iron concentration in water during the ground passage the flow line presented in fig. 1 is chosen.

The largest increase in iron content is noted in the first phase of water flow from ponds to piezometers (from pond 3a to piezometer I r./6), where the average increase is over six times. Then the increase in iron concentration loses its dynamics.

The water flow time from the pond 9 to the piezometer I r./8 was 2 to 3 weeks. Water from pond 9 to the piezometer I r./8 flows mainly in the saturation zone and is filtration (remember that water called infiltration water actually is infiltration water and filtration water). As can be seen, the increase in iron concentration on this flow path is slightly smaller compared to the increase between pond $3 \mathrm{a}$ and piezometer I r./6.

The results are presented in Fig. 4.

Being analyzed in three measurement sequences, the infiltration (infiltration and filtration) process can be summarized as a factor that significantly increases the concentration of iron in water.

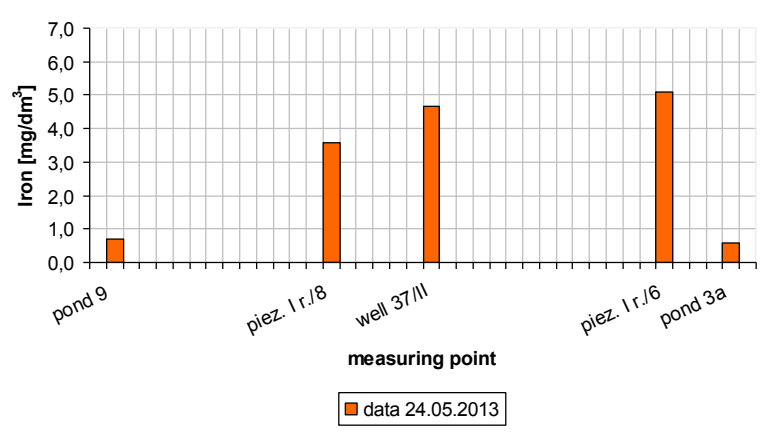

Fig. 4. Change of iron concentration in water by infiltration.

\section{Conclusions}

The research was carried out as a preliminary study, allowing to recognize the process conditions prevailing at Debina intake in Poznan. The methodology used to measure water temperature changes proved to be useful for determining the retention time of infiltration water in the soil. The method is a not chemical way of doing research which does not interfere with the work of the infiltration intake.

The conducted research on the area of the infiltration intake allowed to determine the water retention time in the selected infiltration water flow sequences at Debina intake.

Analysis of iron concentration confirmed the tendency of this parameter to change in infiltration water. The results confirm the existence of a relationship between the retention time and the efficiency of the process.

Recognition of process conditions on the area of Debina infiltration intake allowed exact planning of a further research works with an extended network of measuring points. 
The authors would like to express their thanks for the financial support from research project 01/13/DSPB/0857.

\section{References}

1. Grunheid at al., Wat. Res. 39, (2005)

2. A.K. Thakur C.S.P. Ojha, Int. J. Sediment Res. 25, (2010)

3. Hoffmann A., G. Gunkel, Limnologica 41, (2011)

4. Bartosik, I. Chomicki, T. Jankowski, Ochr. Środ. 3, (2007)

5. Bartosik, I. Chomicki, T. Jankowski, Quality changes of Warta River waters after infiltration process at Debina intake in Poznan (Materials from company AQUANET SA, Poznan, Poland, 2007)

6. Waterworks and sewerage in Poland - tradition and present days (Edit. Polska Fundacja Ochrony Zasobów Wodnych, Poznań - Bydgoszcz 2002)

7. M.J. Miller at al., Wat. Res. 356 (2001)

8. D.W. Metge at al., Wat. Res 44 (2010)

9. T. Heberer at al., Ground Water Monit. Rem. 24, 2 (2004)

10. C.J. Lorenzen at al., Environ. Earth Sci. 61 (2010)

11. R.D. Rakesh at al., Hydrogeol. J. 18 (2010) 